\title{
Advances in management research: a bibliometric overview of the Review of Managerial Science
}

\author{
Alicia Mas-Tur ${ }^{1} \cdot$ Sascha Kraus $^{2}$ (D) Mario Brandtner ${ }^{3} \cdot$ Ralf Ewert $^{4}$. \\ Wolfgang Kürsten ${ }^{3}$
}

Received: 30 June 2020 / Accepted: 1 July 2020 / Published online: 3 August 2020

(c) The Author(s) 2020

\begin{abstract}
The Review of Managerial Science (RMS) is a leading international journal that publishes major advances related to business administration and management. The journal was launched in April 2007 and publishes eight issues per year (from 2021 onwards). The scope of RMS encompasses, but is not limited to, the functional areas of operations (such as production, operations management, and marketing), management (such as human resources management, strategic management, and organizational theory), information systems and their interrelations with capital markets (such as accounting, auditing, finance, and taxation), as well as questions of business strategy, entrepreneurship, innovation, and corporate governance. This study offers a bibliometric overview of the publication and citation structure of RMS from its inception in 2007 until 2020 in terms of topics, authors, institutions, and countries, thereby offering a comprehensive overview of the history of the journal so far. All the data for the study are from the Web of Science Core Collection database. To complement this analysis, VOSviewer software provides graphical analysis. The analysis is based on several bibliometric techniques such as co-citation analysis and bibliographic coupling.
\end{abstract}

Keywords Bibliometrics · Co-citation · Web of science $\cdot$ VOSviewer

JEL Classification M1 $\cdot$ M10 $\cdot$ M19 $\cdot$ M20

Sascha Kraus

sascha.kraus@zfke.de

1 University of Valencia, Valencia, Spain

2 Durham University, Durham, UK

3 Friedrich-Schiller-University of Jena, Jena, Germany

4 Karl-Franzens-University Graz, Graz, Austria 


\section{Introduction}

The Review of Managerial Science (RMS) is an international journal that provides a forum for innovative research from all scientific areas of business administration and management. The scope of RMS encompasses, but is not limited to, the functional areas of operations (such as production, operations management, and marketing), management (such as human resources management, strategic management, and organizational theory), information systems and their interrelations with capital markets (such as accounting, auditing, finance, and taxation), as well as questions of business strategy, entrepreneurship, innovation, and corporate governance. RMS encourages the submission of papers combining ideas and/or approaches from different areas in an innovative way. The journal also welcomes review papers presenting the "state-of-the-art" of a research area and highlighting new directions for further research, a category that has been increasingly neglected in many other journals in recent years. The scientific standards of RMS are guaranteed by a rigorous (at least) double-blind peer review process with ad hoc referees and the journal's international Editorial Board.

RMS first appeared in 2007, with the founding Co-Editors-in-Chief Ralf Ewert (University of Graz, Austria) and Wolfgang Kürsten (University of Jena, Germany), who still lead the journal. Since 2019, the two Editors-in-Chief are supported by a group of Associate Editors which has continuously been extended to accommodate the ongoing constant growth. From August 2020 onwards, this group consists of seven Associates: Ricarda B. Bouncken (University of Bayreuth, Germany; primary area: business strategy \& innovation management), Laura Cabeza-García (University of Léon, Spain; primary area: corporate governance \& corporate social responsibility), Reinhold Decker (Bielefeld University, Germany; primary area: marketing), Fabian Homberg (LUISS University, Rome, Italy; primary area: Human Resource Management), Sascha Kraus (Durham University, UK; primary area: entrepreneurship, SMEs, \& family business), Marc-Steffen Rapp (University of Marburg, Germany; primary area: corporate governance, accounting, \& finance), and Kirsten Thommes (University of Paderborn, Germany; primary area: Human Resource Management).

RMS started by publishing three issues per year and has increased this number over time to eight issues per year from 2021 onwards. The yearly page budget has correspondingly increased from approximately 250 pages in the founding years to around 1100 pages in recent years. The number of submissions strongly increased from approximately 40 during the founding years to more than 540 in 2019. At the same time, the acceptance rate decreased substantially to below $10 \%$ in 2018 and 2019 (see Table 1).

RMS is indexed and abstracted in major databases, including the Social Science Citation Index, Journal Citation Reports/Social Sciences Edition, SCOPUS, and EBSCO Discovery Service. In 2011, the journal's first Journal Citation Reports (JCR) Impact Factor (IF) was announced. Since then, RMS has constantly increased its IF to its current IF of 3.00 in 2019. In Elsevier's SCOPUS database, RMS is currently rated \#25 out of 221 journals in the category "General Business, Management and Accounting" based on its 2019 CiteScore rank of 4.4. Additionally, RMS is rated "B" (on a scale from A to D) in the German VHB Jourqual (JQ3) journal ranking, and it has been listed in the British Academic Journal Guide (ABS) and the French CNRS ratings since their latest editions. 


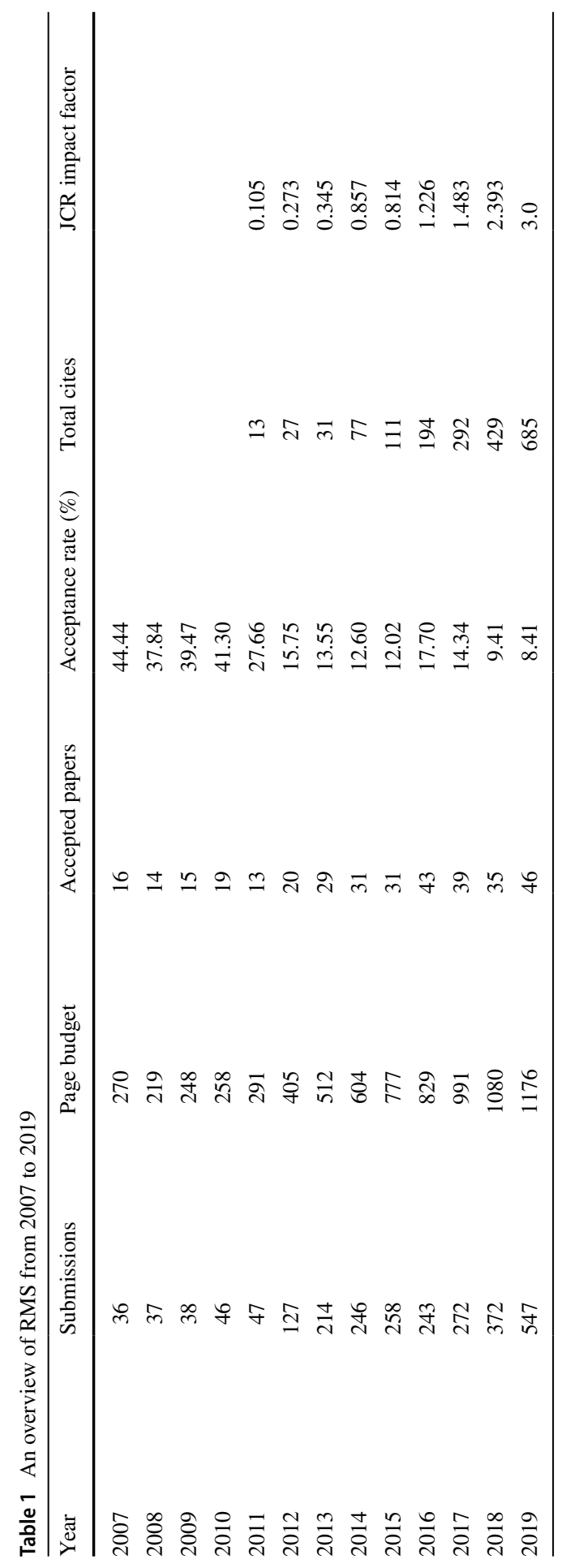


The purpose of this overview study is to examine the main factors that have influenced RMS so far, mainly focusing on the authors, institutions, and countries publishing in the journal, as well as the leading topics that have been published up to now. This in-depth analysis establishes a general overview of the journal's publication structure.

In order to conduct this kind of analysis, several bibliometric techniques are applied. Bibliometrics is a library and information science research field where quantitative methods are used to study bibliographic material (Broadus 1987; Pritchard 1969). Using the Web of Science Core Collection (WoS CC) database, bibliometric analyses enable qualitative study of bibliographic material over the 13-year existence of the journal (2007-2019).

A bibliometric study of a journal is a popular approach for identifying the leading trends of a journal in terms of topics, highly cited papers, authors, institutions, and countries. Many journals have already published bibliometric analyses of their publication and citation structure, with notable examples including Accounting Review (Heck and Bremser 1986), Journal of Financial Economics (Schwert 1993), Technovation (García-Merino et al. 2006; Thongpapanl 2012), Journal of Business Research (Merigó et al. 2015), and Journal of Knowledge Management (Gaviria-Marín et al. 2018).

To thoroughly analyze bibliographic characteristics, mapping techniques are employed as well (Cobo et al. 2011; Small 1999). This article presents analysis of cooccurrences, co-citations, and bibliographic coupling based on the journal's 10-year presence in the Web of Science (WoS) database. The results are visualized using VOSviewer software (Van Eck and Waltman 2010).

\section{Method}

Bibliometrics can be defined as the research field in which the quantitative aspects of bibliographic material are studied (Broadus 1987). Bibliometrics was used as a key concept for the first time by Alan Pritchard in 1969 to replace the ambiguous concept of statistical bibliography (Pritchard 1969). Another term to refer to bibliometrics is scientometrics, which was coined by Nalimov and Mulchenko (1969) to define the study of all aspects of the literature of science and technology (Nalimov and Mulchenko 1969). Finally, Nacke (1979) proposed the term informetrics as a substitute for bibliometrics. Nowadays, bibliometrics, scientometrics, and informetrics are similar key concepts to define the discipline aimed at the quantitative study of bibliographic data (Sengupta 1992; Hood and Wilson 2001).

Bibliometrics is a library and information science research field where bibliographic material is studied using quantitative methods (Broadus 1987; Pritchard 1969). It is very useful for developing a comprehensive overview of the leading trends in a research field, journal, or country (Hood and Wilson 2001). It also enables identification of the most relevant authors on a given topic. A scientometric review provides a holistic approach because it involves a wide coverage of academic research (in this case, 285 publications) and provides objective analysis of a journal or a research field. This extensive review, which is based on a large number of published works, gives a more complete understanding of a journal or research field and can determine the qualitative and quantitative changes that 
occur. Likewise, it enables the creation of maps by generating groups of the main research topics. Essentially, scientometric maps give a holistic view of a particular domain and highlight trends and gaps in research (Suriñach Caralt et al. 2002).

Bibliometric studies are available in a wide range of fields including economics (Coupe 2003), management (Podsakoff et al. 2008), innovation (Fagerberg et al. 2012), entrepreneurship (Landström et al. 2012; Ferreira et al. 2019), family business (Xi et al. 2015), and operations research (Merigó and Yang 2017). In comparison with traditional literature reviews (e.g., Kraus et al. 2020), which are prone to subjective interpretation by researchers, scientometric reviews constitute a methodological innovation (Serrano Bedia et al. 2013). This innovation stems from their use of algorithms, data on production, dispersion, collaboration, and impact indexes (Moya and Prior 2008) to provide objectivity, consistency, and transparency (van Eck and Waltman 2014).

To perform a bibliometric analysis, it is important to define the bibliometric indicators that are used to analyze the data (Merigó et al. 2015). This study considers the number of publications and citations. The number of publications measures productivity, whereas the number of citations reflects popularity and influence. This study also considers the cites-per-paper ratio and the h-index (Hirsch 2005). The h-index indicates the maximum number $(h)$ such that a given author (or journal) has published $h$ papers that have each been cited at least $h$ times. For the country analysis, the results are provided per million inhabitants in order to compare countries with different sizes (Table 7). For the university analysis, the general world ranking of the top universities with authors published in RMS is presented, according to the Academic Ranking of World Universities (ARWU) and the Quacquarelli \& Symonds (QS) University Ranking (Table 6).

The study offers further graphical analysis of the bibliographic data using VOSviewer software (Van Eck and Waltman 2010, 2014). Using this software, two bibliometric techniques are presented: co-citation analysis (Small 1999) and bibliographic coupling (Kessler 1963). A co-citation occurs when two documents receive a citation from the same third document. Bibliographic coupling refers to situations where two studies cite the same third document. Co-citation analysis applies to authors, and bibliographic coupling applies to authors, institutions, and countries.

\section{Results}

In the period 2009 to 2019, RMS published 285 documents indexed in WoS. These 285 documents encompass 248 original papers, 28 review papers, 7 editorials, and 2 other items such as proceedings or corrections. In this bibliometric analysis, 267 documents are considered. Notably, for 2019, 16 articles with early access are excluded. These articles were published online between October and November 2019, but had not been assigned to a regular issue at the time of the study.

Table 2 and Fig. 1 present the annual number of citations of RMS publications, as well as the number of publications reaching a certain citation threshold (more than 100 citations, more than 50 citations, etc.). The number of publications has increased over time. Simultaneously, there was a strong increase in the number of the citations from 2010 (24) to 2011 (296). The last few years show a decline in the number of citations. This decline can be regarded as normal and is due to the lag until articles which 







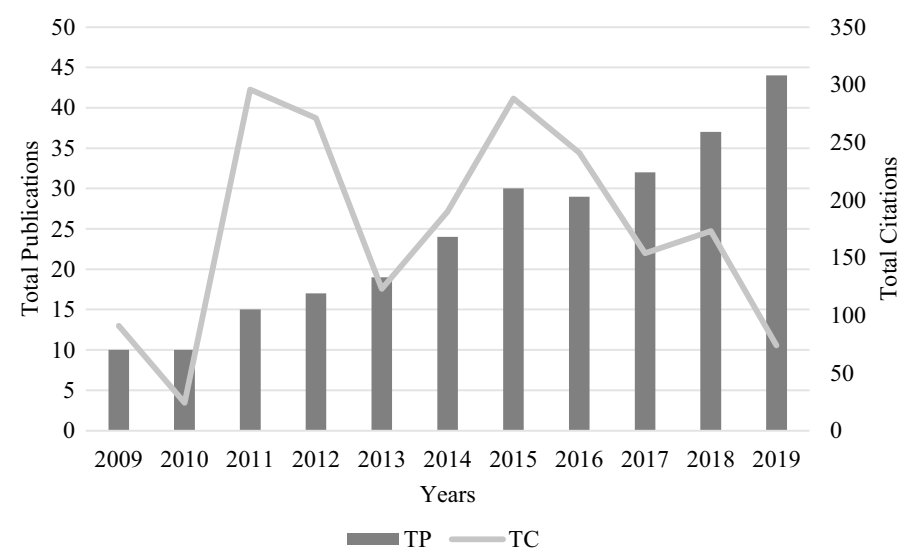

Fig. 1 Annual citation structure of the journal

cite those papers have also undergone the necessary review process before acceptance or publication. Papers published in the years 2013 and 2014 seem to have attracted a smaller audience as well.

Figure 2 shows the evolution of the TOP 5 most cited papers. On an individual basis, three papers have received more than 100 citations: the 2011 paper by Gamerschlag et al. entitled "Determinants of voluntary CSR disclosure: empirical evidence from Germany", the Kraus et al. 2012 paper by Kraus et al. entitled "Entrepreneurial orientation and the business performance of SMEs: a quantitative study from the Netherlands", and the 2015 paper by Bouncken et al. entitled "Coopetition: a systematic review, synthesis, and future research directions". These papers are from three separate subject areas: CSR, entrepreneurship, and strategy.

Another relevant question is, Who cites RMS? The answer indicates the sources of RMS's influence. During the years of 2009 to 2019, RMS received 1643 citations (February 2020). Table 3 presents the journals that have published more than 10 articles citing RMS.

As expected, RMS itself is the journal with the highest number of articles citing RMS publications because the research published in one journal tends to influence future research in the same journal, building an important foundation for the ongoing academic discourse on that topic. The journals Sustainability (90 documents), Corporate Social Responsibility and Environmental Management (37 documents), Journal of Cleaner Production (32 documents), and Journal of Business Research (30 documents) also cite RMS frequently.

In the next step, the relationship between RMS and other journals is analyzed using a co-citation mapping of journals cited by RMS publications (Fig. 3). Co-citations can be defined as two documents that receive a citation from the same third document (Cancino et al.2017). A co-citation mapping is valuable for understanding the clusters of journals that are most closely linked to RMS because they are cited by papers published in RMS. 
There are four main clusters. The first one is led by Strategic Management Journal and Academy of Management Journal, the second is led by Journal of Finance and Journal of Financial Economics, the third is led by Journal of Business Research, and the fourth is led by Entrepreneurship Theory and Practice. The conclusion is that there are four main areas of research cited by the manuscripts published in RMS: management, finance, business, and entrepreneurship.

Table 4 presents a list of the 25 most cited studies published in RMS according to the results found in WoS. In 1927, the first article that used the citation count to evaluate the importance of scientific research was published (Gross and Gross 1927). In the article, the author argues that success breeds success and that a document with many citations is more likely to be cited again than a document with few citations. Similarly, an author with many articles is more likely than a less productive author to publish a new article, and it is more common to refer to a frequently consulted journal than a journal with a small readership (Price 1976). As Joseph (2003) reports, citations can be viewed as the "currency of modern science" (Marsh and Merton 1986; Garfield 1999), and the analysis of citations has become increasingly important to journal editors, authors, and readers (Merigó et al. 2015). The list of the 25 most cited papers reveals three main topics: corporate social responsibility (CSR), business sustainability, and entrepreneurship and management.

In the fields of CSR and business sustainability, the topics of social entrepreneurship and green innovation are receiving considerable attention due to the current concerns related to environmental destruction (Abdullah et al. 2016). The most cited papers in RMS dealing with CSR and business sustainability focus on: (1) voluntary CSR disclosure as a key issue for company visibility, shareholder structure, and the relationship with stakeholders (Gamerschlag et al. 2011); (2) the relationship between CSR disclosure and market valuations, especially in reference to firms operating in environmentally sensitive industries (Reverte 2016); (3) board independence as the main way to enhance the adoption of social activities (Fernández-Gago et al. 2016); and (4) the growth in CSR practices and its effect on managerial discretion (Ferrero et al. 2012). There are two main points that attract scholars' attention in this field of research: CSR disclosure and managerial implications of social activities.

Regarding entrepreneurship and management, Bouncken is a leading author whose research in RMS is focused on different fields of entrepreneurship. (1) Entrepreneurial orientation: Bouncken et al. (2016) focus on entrepreneurial orientation in inter-organizational alliances. From the dynamic capabilities point of view, the authors conclude that the ability to absorb partners' knowledge is a key point to improve joint product innovation; (2) entrepreneurial performance: Bouncken and Reuschl (2018) focus on entrepreneurial performance and opportunism. Opportunism is seen as knowledge leakage, which reduces organizational learning processes by decreasing trust and community building; (3) entrepreneurial coopetition: As previously outlined, Bouncken et al. (2015) focus on coopetition. This is a novel research field, and the authors highlight the importance of developing more theoretical and empirical approaches. They focus on the implications for innovation, taking into consideration the relationship between coopetition and knowledge flow.

In the field of entrepreneurship, some of the most cited papers in RMS deal with family business, focusing on the following topics: (1) internationalization in family 
firms (Mitter et al. 2014); (2) capital structure decisions of family firms (Ampenberger et al. 2013); and (3) corporate reputation and image (Sageder et al. 2018). In all cases, the studies focus on the influence of the family owners on the management of the company.

Table 5 lists the leading authors in terms of publications and impact. To be included in this list, the authors must have more than five citations and at least three publications. In academia, it has long been argued that more than one indicator must be evaluated to determine the overall contribution of an author or institution. Therefore, Table 5 provides different commonly used impact metrics: the total publications of the author, the h-index, the total number of citations, and, as a relative impact approach, the number of citations divided by the number of publications. The leading author in both number of publications and number of citations is Sascha Kraus, whose area of expertise is entrepreneurship, strategic management, and international management.

Finally, when analyzing the location of the authors' affiliation, two main clusters can be found: one consists of authors from German institutions, and the other of authors from Austrian institutions.

Figure 4a, b show the co-citations of authors in RMS. A co-citation (Small 1999; Marshakova-Shaikevich 2005) of authors occurs when the authors of two documents receive a citation from the same author in a third document. Thus, the co-citation establishes the number of documents in which they are cited together.

Figure 4a shows the relationship between authors in RMS, where four different clusters can be detected. This analysis shows that two of the most cited authors, Kraus and Bouncken, are especially related because of their common field of research: entrepreneurship and coopetition.



Fig. 2 Evolution of the citations of the most cited RMS papers 


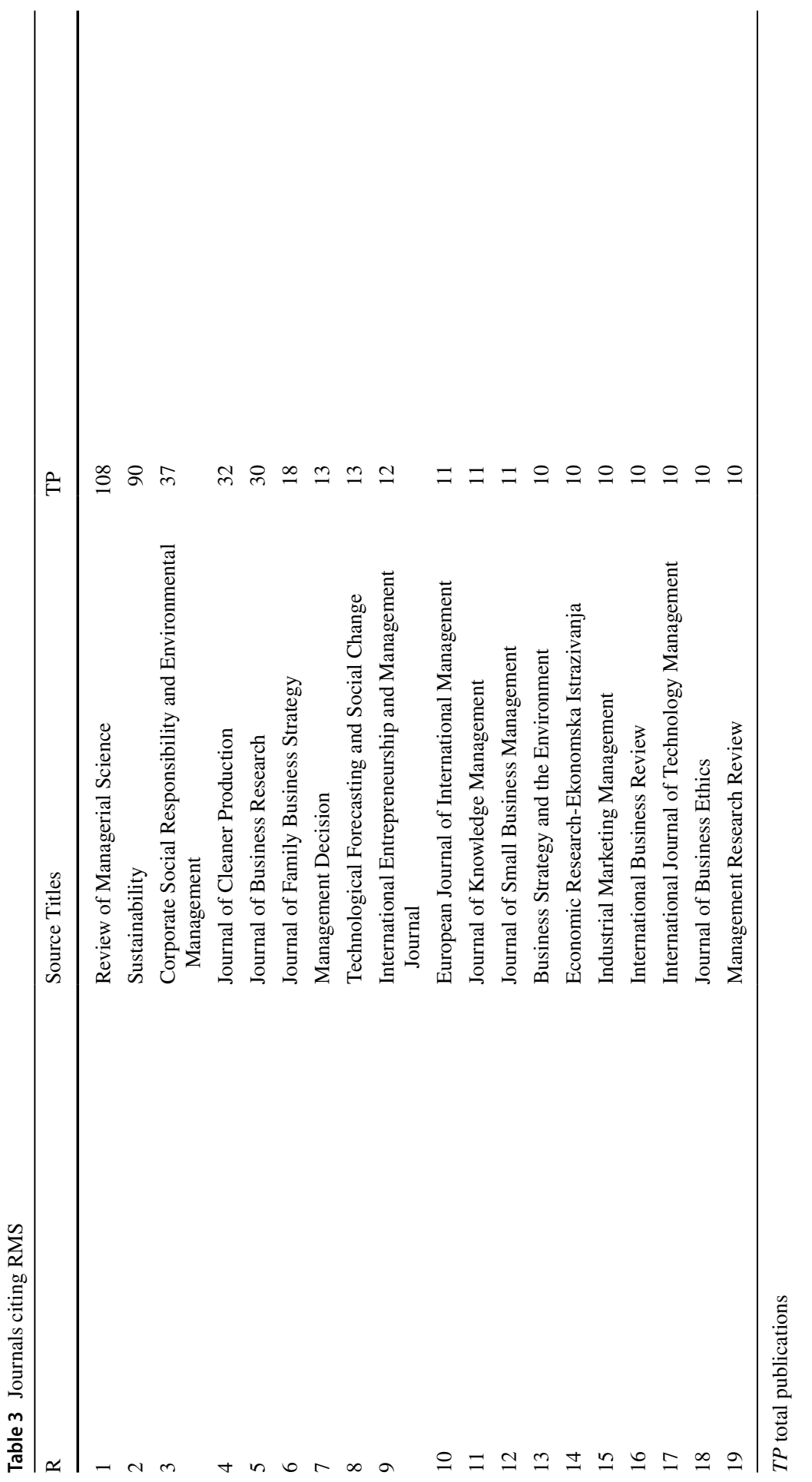




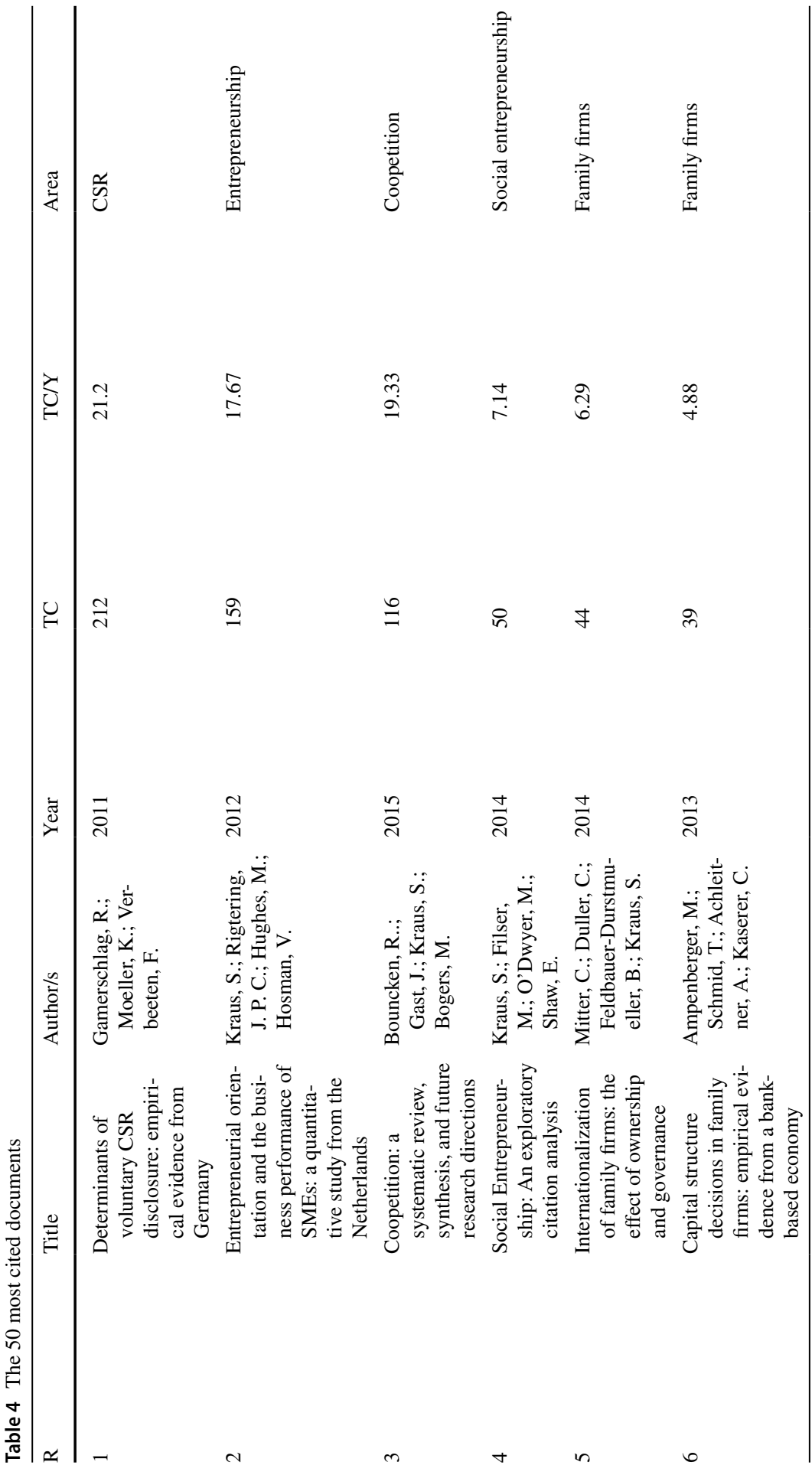




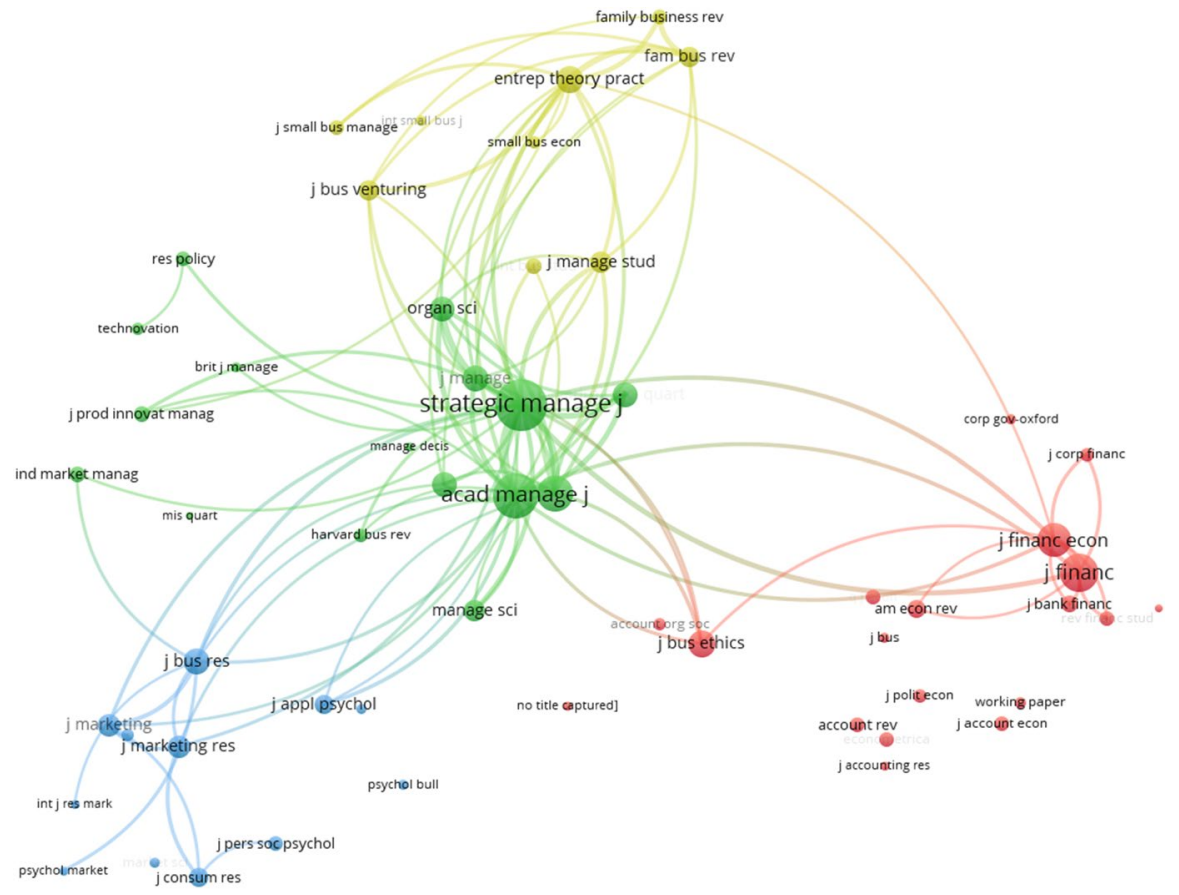

Fig. 3 Co-citation of journals in RMS (minimum citation threshold of 10 and 100 lines)

Figure 4b shows that Kraus, the leading author publishing in RMS according to Table 5, is the link between the clusters. As can be seen from Table 4, Kraus investigates topics related to entrepreneurship, coopetition, and family firms, so it is unsurprising that he has relationships with different clusters.

Figure 5 shows the co-occurrence of author keywords in RMS. Keyword co-occurrence is also called co-word analysis. This analysis links the most used keywords in the published manuscripts to describe the conceptual framework of a research field-in this case, the research focus of RMS (Callon et al. 1983; Courtial 1994; Ding et al. 2001).

Figure 5 displays the evolution of topics in RMS. Table 4 shows that there are two predominant topics addressed in RMS: CSR and family business. This figure also shows the most novel keywords (RMS keywords from 2018 appear in yellow). In the last year, two new key topics appeared: innovation and coopetition.

Table 6 presents the 14 most productive and influential institutions with more than five publications in RMS, ranked by total number of publications. For the university analysis, this study presents the general world ranking of the top universities in RMS, according to the ARWU and the QS University Ranking (Table 6).

Table 6 shows that the University of Regensburg (Germany) tops the ranking. Two members of the RMS Editorial Board belong to this university. One of them, Roland Helm, is the third-ranked author in terms of number of publications. Second and third, with the same number of publications, are Johannes Kepler University of Linz (Austria) and the University of Liechtenstein. 


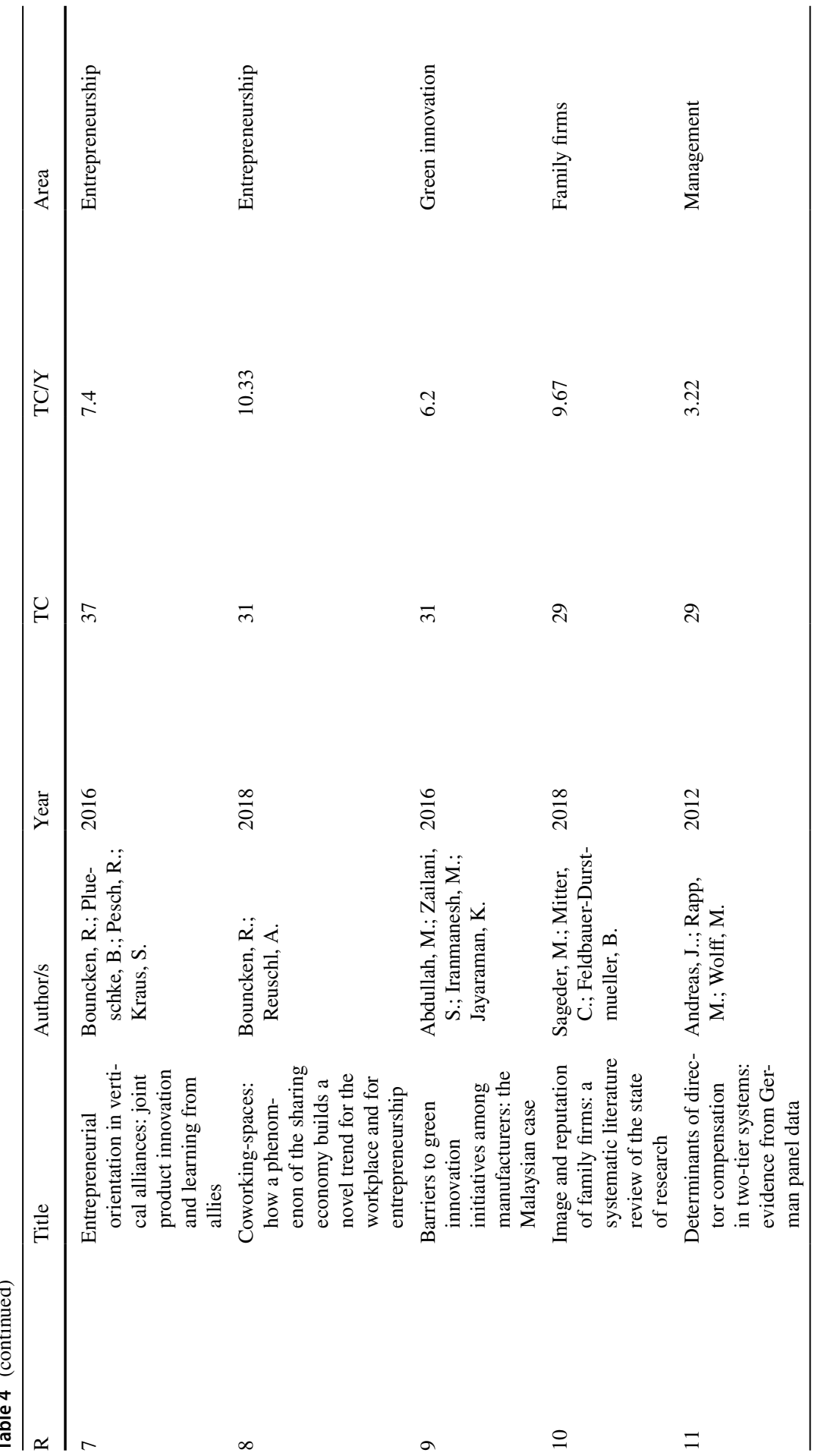




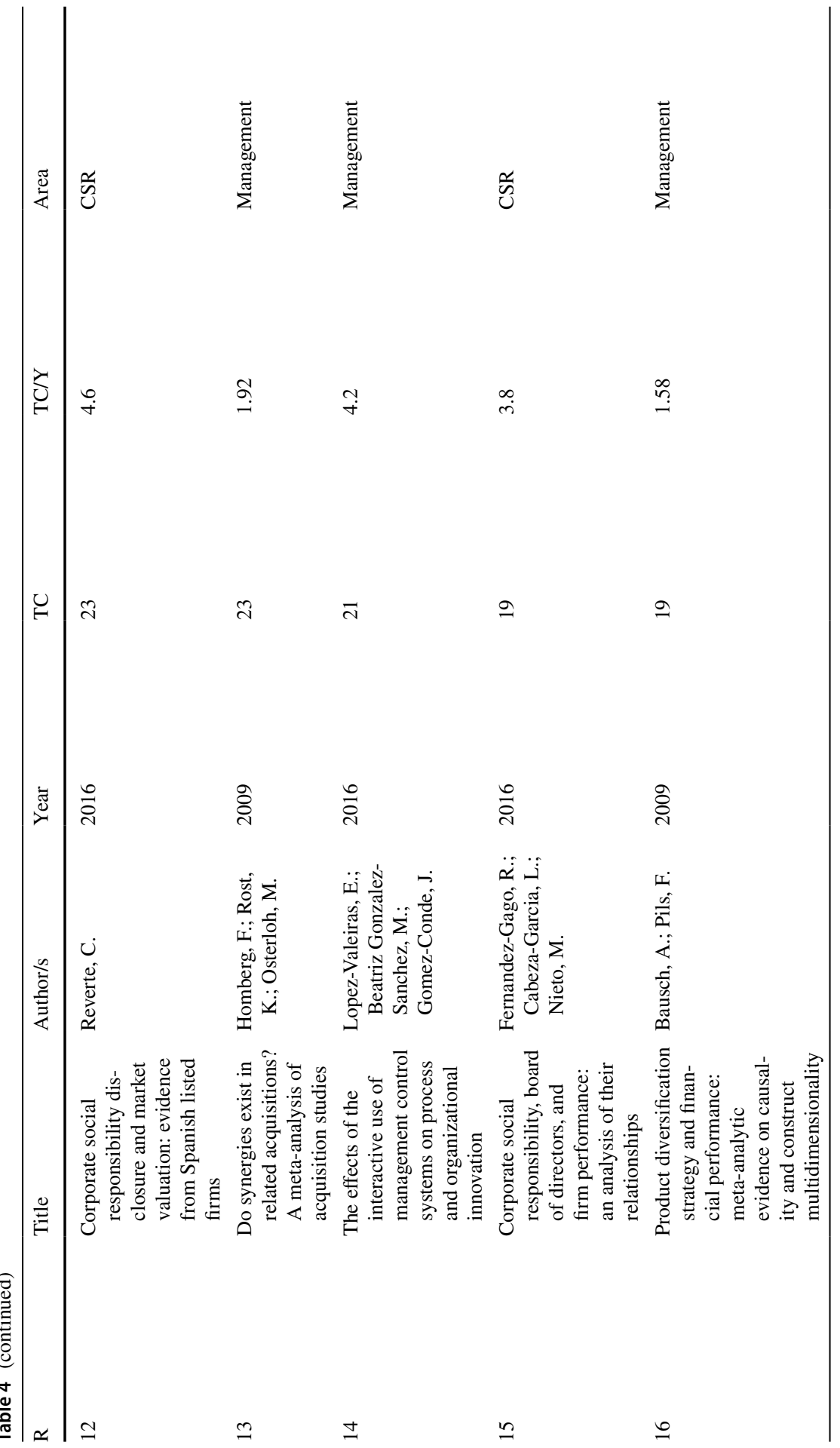




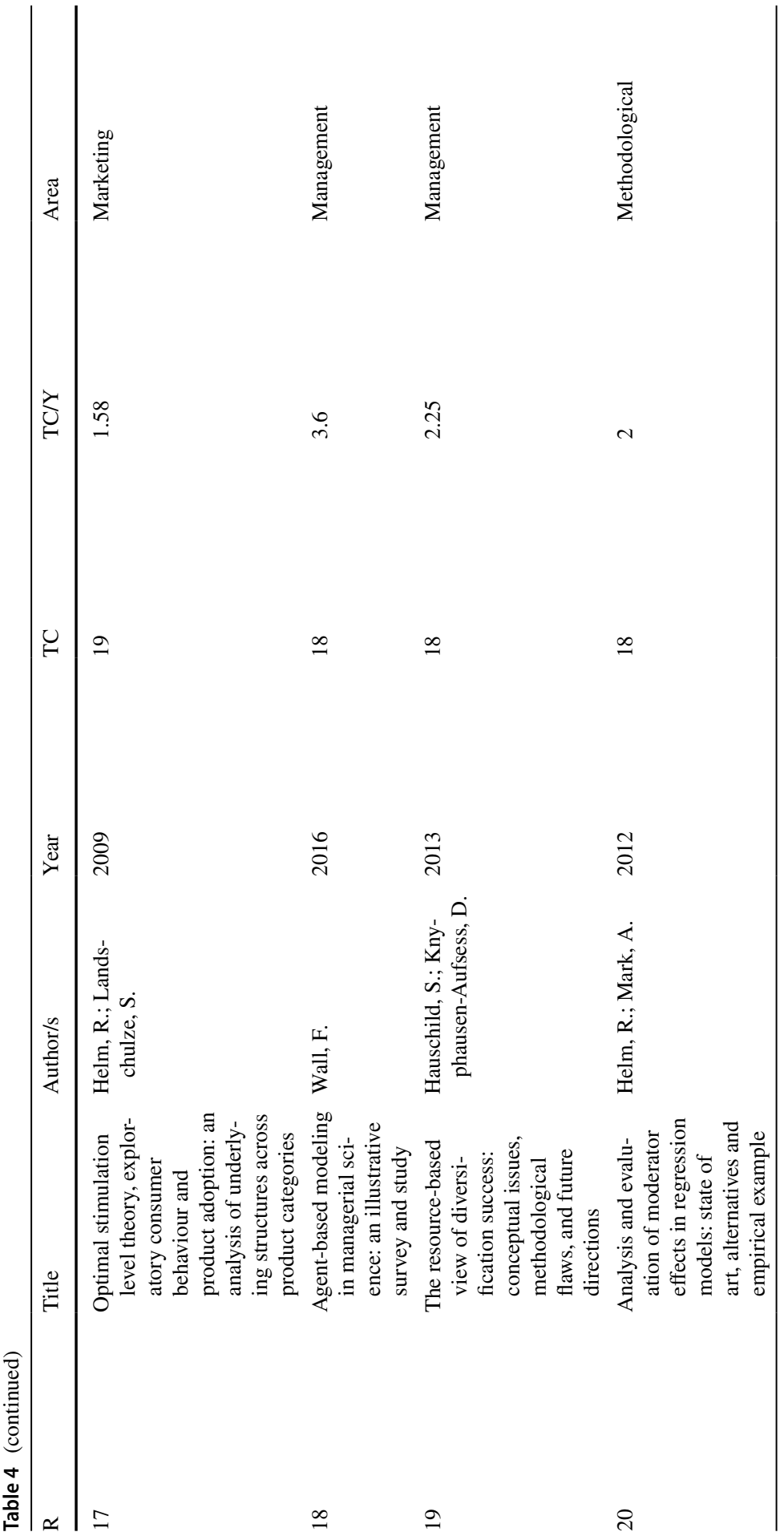














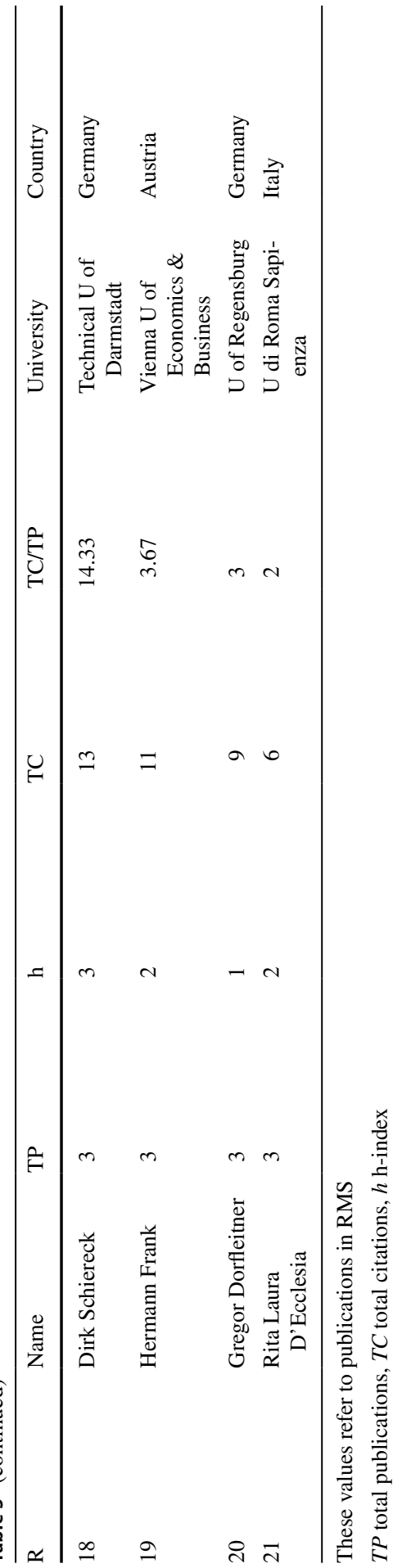






(b)

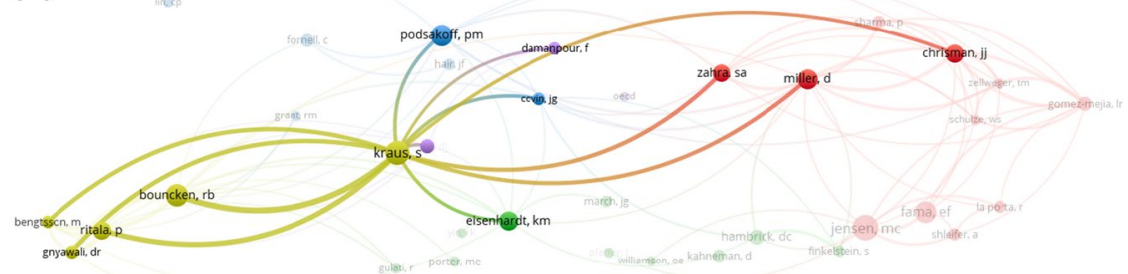

Fig. 4 a Co-citation of authors in RMS (minimum citation threshold of 20 and 100 links). b Co-citation of authors in RMS: one special cluster (minimum citation threshold of 20 and 100 links)



Fig. 5 Co-occurrence of author keywords in RMS (minimum occurrence threshold of 2 and 100 links)

Table 6 shows a strong European cluster. From the 14 universities included in the ranking, 12 are located in Europe. The two non-European institutions are the National Chiao Tung University in Taiwan and the University of Malaya in Malaysia. 


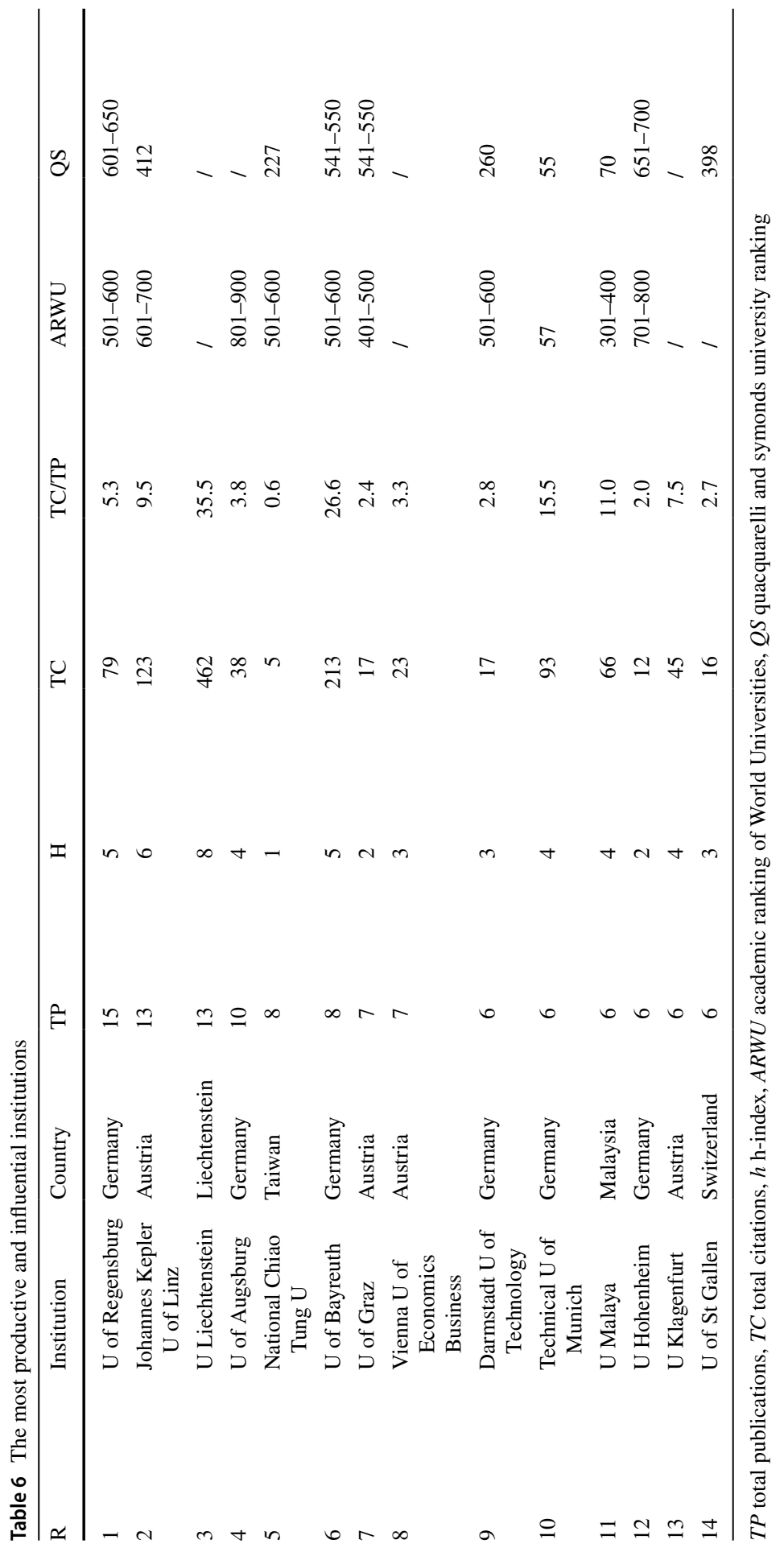




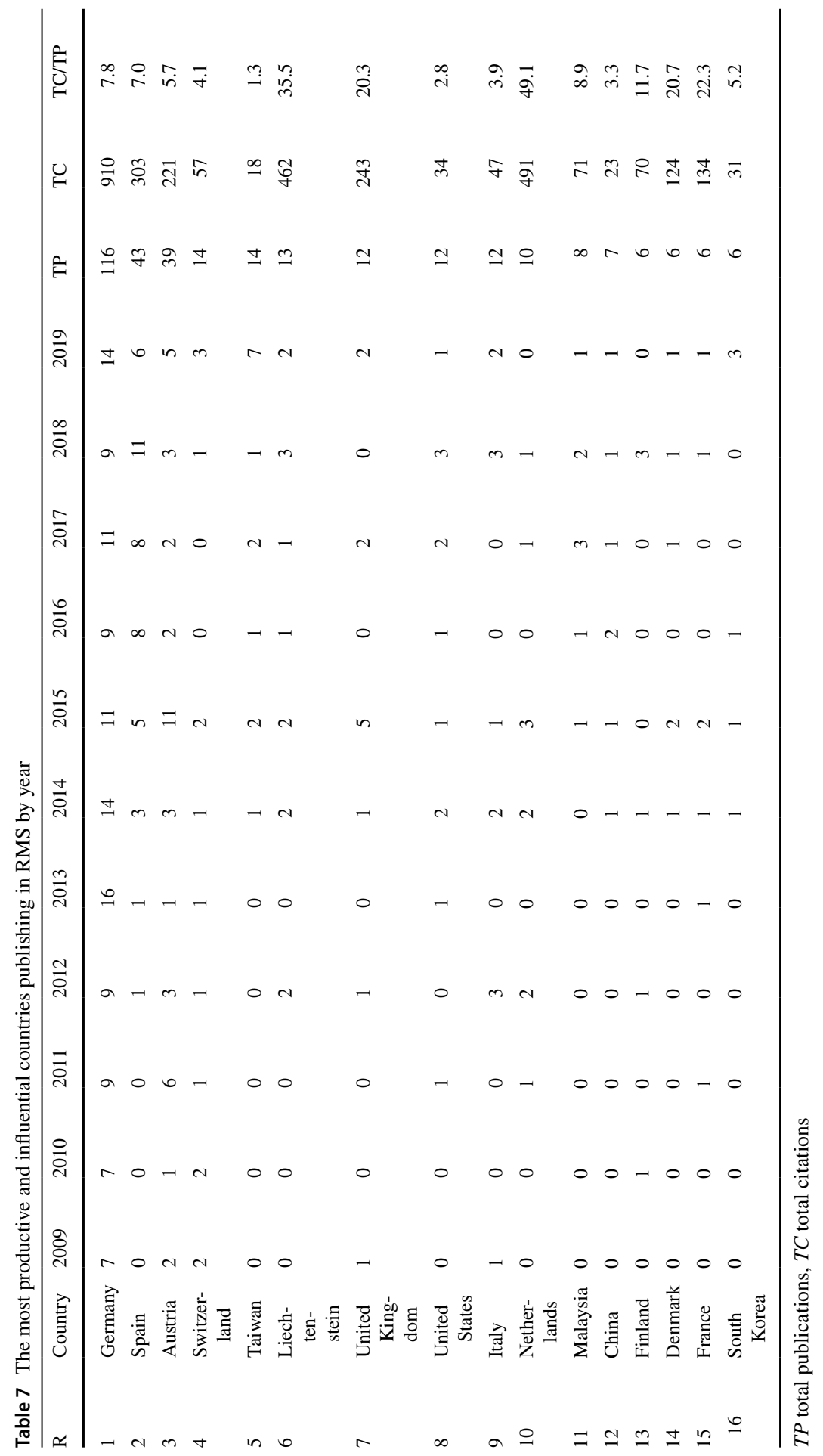




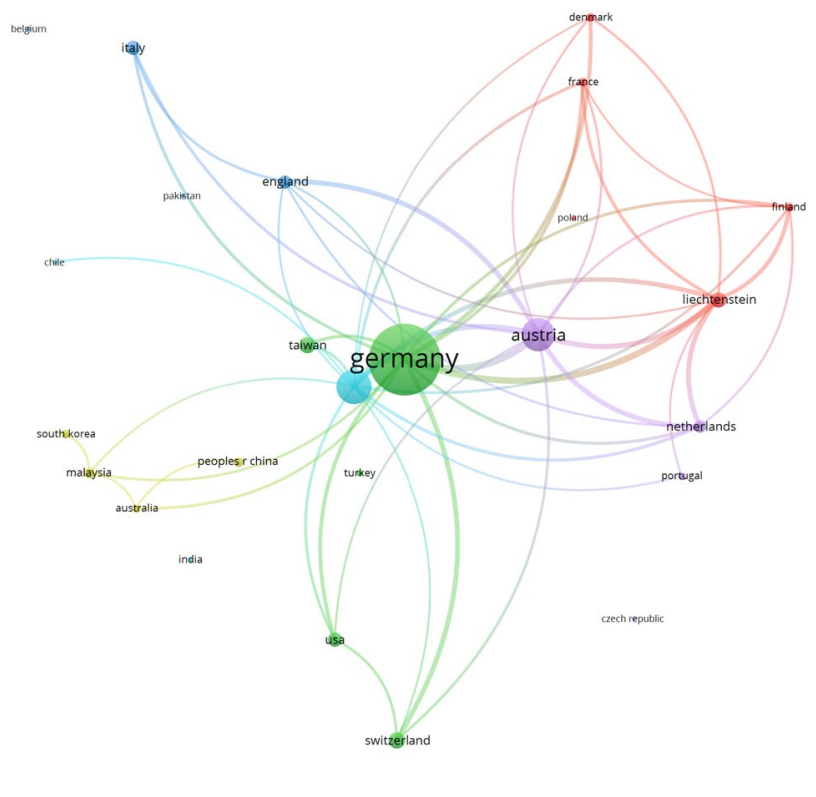

Fig. 6 Bibliographic coupling of countries publishing in RMS (minimum publication threshold of 2 documents and 50 links)

Table 7 represents the annual evolution of contributions by countries. The dominant country in RMS with the most contributions is Germany (91), followed by Spain (33) and Austria (25). For the country analysis, the results are presented per million inhabitants in order to compare countries of different sizes (Table 7).

Figure 6 shows the bibliographic coupling of countries publishing in RMS with a minimum publication threshold of two documents and 50 links. According to Kessler (1963), bibliographic coupling can be defined as the number of shared references by citing documents (that is, two documents that cite the same third document).

As Fig. 6 shows, there are four country clusters. The first cluster contains Germany, Switzerland, Taiwan, and the United States. The second is composed of Spain, Chile, the United States, and Portugal. The third cluster comprises Austria, the Netherlands, Germany, and England. The fourth cluster is made up of Liechtenstein, Finland, Poland, and France. Additionally, there is a fifth cluster. Despite being small, this cluster should be mentioned because it contains countries such as China, South Korea, Malaysia, and Australia, all of which are Asia-Pacific countries that share research with each other.

Germany has by far the most bibliographic couplings and links with all other countries. This is unsurprising since Germany is the most productive and influential country publishing in RMS over time (Table 7). Moreover, Germany also has the most productive and influential institution, with the University of Regensburg (Table 6), and another six German universities appear in Table 6 among the most productive institutions. In addition, Fig. 5 shows other major clusters such as Austria, Taiwan, Liechtenstein, and England. Austria is also present in this research because it is the third country in Table 7. Moreover, four Austrian institutions appear in Table 6, where the most 
productive and influential institutions are shown, and six of the most influential authors belong to this country.

Furthermore, Spain (in blue) is closely related to Germany. Spain is also related to Chile, which is another Spanish-speaking country. As can be seen from Table 7, Spain is the second most productive and influential country. Finally, Fig. 6 shows a close relationship between Germany, Austria, and Liechtenstein. This pattern is unsurprising because this paper has already shown that the authors and institutions from these countries-which all share the same language-are closely linked.

\section{Conclusions}

This study offers an overview of the structure of publications that have appeared in RMS from the journal's launch in 2007 until the end of 2019. To carry out the study, bibliometric indicators from the WoS database are used. The analysis examines the number of citations of RMS by authors and other journals, as well as the most cited articles and the most productive and influential institutions and countries. In addition, the bibliometric study is complemented by VOSviewer analysis, which provides graphical analysis of the clusters of research topics, countries, and authors in the journal.

The results show a strong increase in publications and citations over time. It is worth highlighting the high impact of the articles published by the main authors, since they have managed to receive citations of all their articles published in RMS. The results also indicate that Germany is the leading country in the journal in terms of impact, followed by Spain, Austria, and Switzerland. In a similar vein, the most influential institution is the University of Regensburg in Germany, with a total of 15 publications, followed by other European universities. In addition, the VOSviewer analysis shows that Germany has the most bibliographic couplings and links with other countries.

Regarding the clusters obtained from the VOSviewer analysis of knowledge areas and topics, there are four main areas of research cited by the manuscripts published in RMS: management, finance, business, and entrepreneurship. Within these areas, there are two dominant topics in the journal's publications throughout its history: CSR and family business. However, innovation and coopetition have recently become increasingly cited topics.

Although this study offers a comprehensive analysis of the main RMS publications, it of course has some limitations. The study of the journal's publications refers to the period since the journal's inception. Accordingly, the earliest published articles have normally received more citations than the most recent ones, even if the latter might be more influential; their long-term impact might not yet have been seen. Furthermore, by their very nature, the analyses are descriptive as well as backward-oriented. They can serve very well for presenting the past but can only give limited information about upcoming future trends in terms of the topics which will become influential. What can be concluded already, however, is that the journal is continuing to rise. As a result of the high quality of its publications, RMS has been indexed in the WoS since 2011, just four years after its launch. This achievement shows the high degree of interest of authors and readers in the topics of the journal, as well as its academic impact. Also the JCR Impact Factor is constantly increasing. RMS currently holds a JCR Impact Factor of 3.0 (as of 
2019), and it is ranked in the second quartile of the "Management" category. RMS has gained international appeal and is continuing to actively shape academic discourse in several areas of management science.

All in all, RMS continues to welcome contributions from all areas within the wider business and management continuum that, regardless of the chosen method (quantitative, qualitative, mixed methods, experimental, conceptual, as well as review articles or meta-analyses, but usually excluding single case studies, student samples or samples from one single geographical area-such as cities or regions-with limited representativeness or generalizability), have the potential to set new foundations for a prominent future academic discourse within the journal and beyond.

Open Access This article is licensed under a Creative Commons Attribution 4.0 International License, which permits use, sharing, adaptation, distribution and reproduction in any medium or format, as long as you give appropriate credit to the original author(s) and the source, provide a link to the Creative Commons licence, and indicate if changes were made. The images or other third party material in this article are included in the article's Creative Commons licence, unless indicated otherwise in a credit line to the material. If material is not included in the article's Creative Commons licence and your intended use is not permitted by statutory regulation or exceeds the permitted use, you will need to obtain permission directly from the copyright holder. To view a copy of this licence, visit http://creativecommons.org/licen ses/by/4.0/.

\section{References}

Abdullah M, Zailani S, Iranmanesh M, Jayaraman K (2016) Barriers to green innovation initiatives among manufacturers: the Malaysian case. RMS 10(4):683-709

Ampenberger M, Schmid T, Achleitner AK, Kaserer C (2013) Capital structure decisions in family firms: empirical evidence from a bank-based economy. RMS 7(3):247-275

Bouncken RB, Reuschl AJ (2018) Coworking-spaces: how a phenomenon of the sharing economy builds a novel trend for the workplace and for entrepreneurship. RMS 12(1):317-334

Bouncken RB, Gast J, Kraus S, Bogers M (2015) Coopetition: a systematic review, synthesis, and future research directions. RMS 9(3):577-601

Bouncken RB, Plüschke BD, Pesch R, Kraus S (2016) Entrepreneurial orientation in vertical alliances: joint product innovation and learning from allies. RMS 10(2):381-409

Broadus R (1987) Toward a definition of "bibliometrics". Scientometrics 12(5-6):373-379

Callon M, Courtial JP, Turner WA, Bauin S (1983) From translations to problematic networks: an introduction to co-word analysis. Information (International Social Science Council) 22(2):191-235

Cancino CA, Merigó JM, Coronado FC (2017) A bibliometric analysis of leading universities in innovation research. J Innovations Knowl 2(3):106-124

Cobo MJ, López-Herrera AG, Herrera-Viedma E, Herrera F (2011) Science mapping software tools: review, analysis, and cooperative study among tools. J Am Soc Inform Sci Technol 62(7):1382-1402

Coupe T (2003) Science is golden: academic R\&D and university patents. J Technol Transf 28(1):31-46

Courtial J (1994) A coword analysis of scientometrics. Scientometrics 31(3):251-260

Ding Y, Chowdhury GG, Foo S (2001) Bibliometric cartography of information retrieval research by using co-word analysis. Inf Process Manag 37(6):817-842

Fagerberg J, Fosaas M, Sapprasert K (2012) Innovation: exploring the knowledge base. Res Policy 41(7):1132-1153

Ferrero-Ferrero I, Fernández-Izquierdo MÁ, Muñoz-Torres MJ (2012) The impact of the board of directors characteristics on corporateperformance and risk-taking before and during the global financial crisis. Rev Manag Sci 6(3):207-226

Fernández-Gago R, Cabeza-García L, Nieto M (2016) Corporate social responsibility, board of directors, and firm performance: an analysis of their relationships. RMS 10(1):85-104

Ferreira JJ, Fernandes CI, Kraus S (2019) Entrepreneurship research: mapping intellectual structures and research trends. RMS 13(1):181-205 
Gamerschlag R, Möller K, Verbeeten F (2011) Determinants of voluntary CSR disclosure: empirical evidence from Germany. RMS 5(2-3):233-262

García-Merino MT, Pereira-do-Carmo ML, Santos-Álvarez MV (2006) 25 years of Technovation: characterisation and evolution of the journal. Technovation 26(12):1303-1316

Garfield E (1999) Journal impact factor: a brief review

Gaviria-Marín M, Merigó JM, Popa S (2018) Twenty years of the Journal of Knowledge Management: a bibliometric analysis. J Knowl Manag 22:1655-1687

Gross PL, Gross EM (1927) College libraries and chemical education. Science 66(1713):385-389

Heck JL, Bremser WG (1986) Six decades of the accounting review: a summary of author and institutional contributors. Account Rev 61(4):735-744

Hirsch JE (2005) An index to quantify an individual's scientific research output. Proc Natl Acad Sci 102(46):16569-16572

Hood W, Wilson C (2001) The literature of bibliometrics, scientometrics, and informetrics. Scientometrics 52(2):291-314

Joseph KS (2003) Quality of impact factors of general medical journals. BMJ 326(7383):283

Kessler MM (1963) Bibliographic coupling between scientific papers. Am Doc 14(1):10-25

Kraus S, Rigtering JC, Hughes M, Hosman V (2012) Entrepreneurial orientation and the business performance of SMEs: a quantitative study from the Netherlands. RMS 6(2):161-182

Kraus S, Breier M, Dasí-Rodríguez S (2020) The art of crafting a systematic literature review in entrepreneurship research. Int Entrep Manag J. https://doi.org/10.1007/s11365-020-00635-4

Landström H, Harirchi G, Åström F (2012) Entrepreneurship: Exploring the knowledge base. Res Policy 41(7):1154-1181

Marsh TA, Merton RC (1986) Dividend variability and variance bounds tests for the rationality of stock market prices. Am Econ Rev 76(3):483-498

Marshakova-Shaikevich I (2005) Bibliometric maps of field of science. Inf Process Manag 41(6):1534-1547

Merigó JM, Yang JB (2017) A bibliometric analysis of operations research and management science. Omega 73:37-48

Merigó JM, Mas-Tur A, Roig-Tierno N, Ribeiro-Soriano D (2015) A bibliometric overview of the Journal of Business Research between 1973 and 2014. J Bus Res 68(12):2645-2653

Mitter C, Duller C, Feldbauer-Durstmüller B, Kraus S (2014) Internationalization of family firms: the effect of ownership and governance. RMS 8(1):1-28

Moya S, Prior D (2008) ¿Quién publica en las revistas españolas de contabilidad? Análisis bibliométrico del periodo 1996-2005. Spanish J Finance Accounting/Revista Española de Financiación y Contabilidad 37(138):353-374

Nacke O (1979) Informetrics-definition, status of knowledge and development of principles. Nachrichten Fur Dokumentation 30(6):219-226

Nalimov VV, Mulchenko BM (1969) Scientometrics. Studies of science as a process of information. Science, Moscow

Podsakoff PM, MacKenzie SB, Podsakoff NP, Bachrach DG (2008) Scholarly influence in the field of management: a bibliometric analysis of the determinants of university and author impact in the management literature in the past quarter century. J Manag 34(4):641-720

Price R (1976) The Guiana maroons: a historical and bibliographical introduction. Johns Hopkins University Press, Baltimore, p 12

Pritchard A (1969) Statistical bibliography or bibliometrics. J Doc 25(4):348-349

Reverte C (2016) Corporate social responsibility disclosure and market valuation: evidence from Spanish listed firms. RMS 10(2):411-435

Sageder M, Mitter C, Feldbauer-Durstmüller B (2018) Image and reputation of family firms: a systematic literature review of the state of research. RMS 12(1):335-377

Schwert GW (1993) The Journal of Financial Economics: a retrospective evaluation (1974-1991). J Financ Econ 33(3):369-424

Sengupta JK (1992) A fuzzy systems approach in data envelopment analysis. Comput Math Appl 24(8-9):259-266

Serrano Bedia AM, López Fernández MC, Pérez Pérez M (2013) Análisis de la relación entre flexibilidad en operaciones y performance empresarial mediante técnicas bibliométricas

Small H (1999) Visualizing science by citation mapping. J Am Soc Inf Sci 50(9):799-813 
Suriñach Caralt J, Duque JC, Ramos Lobo R, Royuela Mora V (2002) La investigación regional en España: un análisis bibliométrico. Documents de treball (Facultat d'Economia i Empresa. Espai de Recerca en Economia), 2002, E02/89

Thongpapanl NT (2012) The changing landscape of technology and innovation management: an updated ranking of journals in the field. Technovation 32:257-271

Van Eck NJ, Waltman L (2010) Software survey: VOSviewer, a computer program for bibliometric mapping. Scientometrics 84(2):523-538

Van Eck NJ, Waltman L (2014) Visualizing bibliometric networks. In: Ding Y, Rousseu R, Wolfram D (eds) Measuring scholarly impact. Springer, Cham, pp 285-320

Xi JM, Kraus S, Filser M, Kellermanns FW (2015) Mapping the field of family business research: past trends and future directions. Int Entrep Manag J 11(1):113-132

Publisher's Note Springer Nature remains neutral with regard to jurisdictional claims in published maps and institutional affiliations. 